Article

\title{
Dynamic Modeling for Life Cycle Cost Analysis of BIM-Based Construction Waste Management
}

\author{
Milad Zoghi ${ }^{1}$ and Sungjin Kim ${ }^{2, *}$ \\ 1 Department of Civil Engineering, K.N. Toosi University of Technology, Tehran 1417466191, Iran; \\ miladzoghi@aut.ac.ir \\ 2 Department of Civil, Construction, and Environmental Engineering, University of Alabama, 401 7th Ave. \\ 264 Hardaway Hall, Box 807025, Tuscaloosa, AL 35487, USA \\ * Correspondence: sungjin.kim@eng.ua.edu; Tel.: +1-205-348-0369
}

Received: 22 January 2020; Accepted: 19 March 2020; Published: 22 March 2020

check for updates

\begin{abstract}
Recent studies in construction waste and management (CWM) have mainly investigated the waste management chain from a static perspective and failed to take into account the dynamic nature of parameters and their correlation. In addition, the current studies of building information modeling (BIM)-based CWM failed to analyze the cost-benefits due to the lack of numerical economic benchmarks. To address the gap, this study developed a system dynamic (SD) model to analyze the economic aspects of construction and demolition (C\&D) waste from using BIM. Causal loop and stock-flow diagrams are modeled based on the determined variables and their interrelationships. Standard sensitivity tests were then performed to establish the validity of the model under real system conditions. Different scenarios were applied to simulate and compare the model results in response to various policies. A case study was conducted to quantify the costs and the profits. Based on the comparison with the conventional approach and BIM-based method, BIM can reduce CWM cost by up to $57 \%$. The findings also indicated that higher landfill charges will not be able to motivate managers to use sustainable CWM; conversely, increasing the modularity of design and earlier realization of net benefits will incentivize project managers to employ BIM-based CWM.
\end{abstract}

Keywords: building information modeling; system dynamic; life cycle cost; construction waste management; sustainable waste management

\section{Introduction}

The construction industry is one of the major sources of environmental pollution and energy use in the world. One of the most destructive factors contributing to the adverse repercussions of construction activities is construction and demolition (C\&D) waste produced in different stages of a construction project [1]. Overwhelming amounts of greenhouse gases produced, energy consumed, land occupied, soil and water contaminated, and raw minerals used result in massive waste generation, imposing economic, social, and environmental problems in developed and underdeveloped countries [2,3]. According to the United States Environmental Protection Agency (EPA), approximately 569 million tons of C\&D debris were generated in 2017, the majority from concrete waste and asphalt $(69.7 \%$ and $15 \%$, respectively) [4]. Generally, building-related construction debris includes steel, drywall, plaster, clay tile and brick, wood products, asphalt shingles, and concrete, all of which are excluded from municipal solid waste.

Such a large percentage of waste disposal indicates that waste that could have been recycled or reused is being dumped without proper treatment. This imposes a huge pressure on stakeholders and project managers to progress toward the mission of sustainability [5]. Effective construction waste management (CWM) would offer numerous benefits, including reducing landfill cost, decreasing 
greenhouse gas emissions, lowering the amount of virgin materials extracted, and conserving land and water [6]. The benefits of proper CWM are not limited to environmental issues. They are also useful in economic and social terms. Pillars of sustainability have been assessed through various sustainable tools and frameworks in past research. For example, the management of C\&D waste in the United States in 2017 not only contributed approximately $\$ 14$ billion to government coffers, but also provided more than 13,000 job opportunities [4]. In this regard, analyzing the cost-benefit of C\&D waste management can motivate project managers to follow sustainable approaches. Additionally, a grievous problem in developed and developing countries alike, construction waste has attracted a great deal of attention among researchers [7].

In the last decade, building information modeling (BIM) has been used to optimize various features of C\&D activities [8]. BIM equips owners with visual tools and detailed information about selected activities and materials. Thus, analyzing project life cycle costs of projects on the BIM platform increases the accuracy and consistency of the results. Yuan and Shen quantified the cost-benefit of using BIM in CWM, where all material prices, recycling and deconstructing costs, and profits from selling salvage materials could be examined [9]. In this study, the implementation of state-of-the-art measurements and practices depended heavily on quantified measurements and estimations that could be referenced as benchmarks for decision-making in the construction industry [9]. The current state of knowledge has made substantial contributions to exploring theoretical aspects of using BIM in construction waste minimization. However, CWM is considered as a complicated system that includes various and dynamic activities, such as recycling, reusing, sorting, and transporting, and these processes require dynamic considerations of all effective variables and their interrelationships [10]. For instance, the potential for recyclability and reusability at the end of a building's life is significantly influenced by the sustainable materials selected during the design stage and the amount of maintenance at the operation stage [11,12].

Although much research has been conducted in the BIM-enabled CWM areas, there are still some major issues awaiting further examination. The first is lack of consideration of the dynamic nature in using BIM for CWM, which leads to overlooking the existing potentials at different stages of a building's life; the second is the lack of decent tools for making decisions on the different dynamic dimensions of BIM applications; and finally, the third point is a need for a quantitative assessment of BIM's capabilities in reducing CWM costs, which helps stakeholders and managers to estimate and measure the true size of the CWM costs and benefits. Given these research gaps, the primary aim of this study is to propose a system dynamic (SD) model to evaluate the cost-benefits of BIM-based CWM, because the SD approach originated by Forrester can assess dynamic problems characterized by interdependence, information feedback, circular causality, and mutual interaction [13]. By using the SD method, the main contributions of this study are the development of an SD model depicting the dynamic nature of BIM-integrated CWM and the interrelations between the causes and effects in the system environment and analyzing the cost-benefit of BIM-based CWM under the various scenarios. To validate the model, the case study was conducted, and the results were compared with the traditional CWM (non-BIM-integrated). This presented study can contribute to documenting a numerical benchmark for the stakeholders to use the BIM in the CWM in more sustainable manner.

\section{Literature Review}

In light of the increasing rate of waste generation (RWG) and its impact, numerous studies have been conducted on waste reduction potentials at different stages of a building's life cycle, including design, construction, maintenance, and demolition. Vivian et al. [14] listed the main reasons for material waste in the construction processes. Damage occurring during transportation, such as cracked stone or settled concrete, storage of excessive amount of materials, lack of precision in measuring elements like rebar, use of non-recyclable items, inconsistency in design drawings, and a lack of cooperation between contractors and managers have all been highlighted as primary reasons for generating waste. For instance, approximately $1.5 \%$ of the total mixed concrete materials settled due to 
long transportation times [14]. Researchers have argued that non-standard designs [15], inappropriate handling of materials [16], and unexpected change of order requests could raise the quantity of C\&D waste by as much as 33\% [17]. The low potential for successful disassembly and recyclability in the final phase of a building's life does not motivate project managers and stakeholders to invest in sustainable CWM procedures. Many strategies and copious technology have been proposed to alleviate these problems, as addressed below.

\subsection{BIM in CWM}

BIM is a tool of data communication and spatial analysis for integrating data acquisition, exchange, and visualization during the construction project life cycle [18]. The BIM platform assists managers and engineers by enhancing the quality of design and construction activities. The main features include synching all information in a unique model and simplifying data capture and visualization of the model [19]. Researchers have shown that BIM-based design validation reduces errors and the need for rework by allowing for design review and clash detection, reducing waste generation by up to $15 \%$ [20]. Rajendran and Gomez found that zero waste goals could be achieved through BIM implementation in the construction project [21]. Analyzing the main causes of waste generation, Ahankoob et al. investigated the potential functionality of BIM in reexamining design performance in order to reduce errors, rework, and awkward clashes [22].

During the building maintenance and operation phase, BIM capabilities support residents and stakeholders by allowing them to share required technical information on facilities and equipment, making time-based maintenance more effective [23]. Ngwepe and Aigbavboa claimed that a significant volume of spare parts was wasted by repairing or servicing constructed facilities (e.g., fixtures, lighting, and heating and cooling systems) [24]. Products were also being consumed through refurbishment processes like cleaning and decorating. All of these factors could be avoided through preventive maintenance [25]. Despite the fact that most waste is generated at the end of a building's lifespan, setting a benchmark that encompasses the whole building's life cycle is necessary [26]. Guy and Ciarimboli highlighted the concept of design for deconstruction (DfD) in BIM studies [27]. DfD refers to the rules to be followed at the design stage in order to facilitate the separability of the elements at the end of the building's life cycle. Key DfD principals are mentioned in Table 1.

Table 1. Design for deconstruction (DfD) principles relevant to waste generation rate.

\begin{tabular}{cc}
\hline Principle & Reference \\
\hline Avoiding toxic materials & Macozoma [28] \\
Using high-durability materials & Tingley and Davison [29] \\
Using the minimum number of connections & Fishbein [30] \\
Retaining building information & Macozoma [28] \\
Using reusable and recyclable materials & Macozoma [28] \\
Using bolts in joints instead of welding & Chini and Balachandran [31] \\
Using prefabricated materials & Jaillon et al. [15] \\
Avoiding nails and adhesives & Jaillon et al. [15] \\
\hline
\end{tabular}

Despite its importance, only a few studies have provided quantitative assessments of BIM use in CWM. In a case-study, Wong et al. used BIM to measure the amount of waste produced without detecting clashes [6]. This study proved that clash detection could reduce construction waste from $4.3 \%$ to $15.2 \%$. Jalaei et al. developed an add-on to the BIM that quantifies the amount of waste prevented by different BIM potentials and the resulting environmental impacts [8] in that the proposed framework showed that BIM could reduce the energy consumed and $\mathrm{CO}_{2}$ emitted by about $66.1 \mathrm{MJ}$ and $62.2 \%$, respectively. However, the abovementioned strategies have not been adopted in practice as widely as was anticipated. The main explanation for this is a lack of economic incentives that inhibit project managers from becoming involved in sustainable CWM activities. The profitability of CWM depends on landfill and sorting cost, as well as the selling price of reusable and recyclable materials, which is 
based on their quality and the level of maintenance [32]. Uncertainty of the benefits from CWM is a byproduct of the dynamic nature inevitable in long-term construction projects [10].

\subsection{SD Approach in CWM}

Current research evaluating the role of BIM in CWM has solely focused on optimizing and enhancing the quality of various construction activities without considering the dynamic aspects of certain variables on an industrial scale. SD has been used to investigate the behavior of complex systems and their underlying structures over time. This approach has been widely used in various areas of the construction industry to help predicting the impacts and making confident policy and strategy choices. For example, Kim et al. developed an SD model to predict how the skilled labor shortage has an impact on construction project management [33].

Many studies have applied an SD approach to investigate the CWM. Yuan et al. assessed the cost-benefits of conventional CWM using SD [10]. Landfill charges, public dissatisfaction, and illegal dumping were employed as the main variables in order to assess the social performance of generated waste [1]. Wang et al. outlined the benefits of using an SD approach in the selection of sustainable materials during the design stage [11]. Kollikkathara et al. proposed a dynamic model of the cost-benefits of municipal waste management based on remaining landfill capacity [34]. Although a wide variety of research has been conducted by using the SD model to estimate multifaceted aspects of generated waste, no studies have encompassed the dynamic impacts of waste minimization and management within a building's life cycle through sustainable design. In addition, no research has dealt with the dynamic aspect of using BIM on an industrial scale; rather, all studies have focused on qualitative assessments of individual buildings.

The simulation-based method is very popular and suitable for describing the dynamic nature of microeconomic phenomena and is able to represent the mechanism of interrelationships between variables and the effects as an objective method [35,36]. On this CWM-related topic, an SD approach was utilized in multifarious research within the broad discipline of CWM, such as in estimating the amount of municipal solid waste [37], tracking and controlling hospital waste [38], and analyzing cost-benefits of CWM [10]. Therefore, in this study, an SD model was proposed to comprehensively assess BIM proficiencies and consider fluctuations in all variables as well as their interrelationships over time. Based on the developed SD model, this present research analyzed in numerical terms the possible decreases in waste management cost that are achievable through BIM-based CWM. To develop the SD model, Vensim software was used in this study because it is user-friendly and very powerful with regards to the mathematical programming equations that govern relationships [11].

\section{System Dynamic Model Development}

This paper developed an SD model to simulate the CWM procedure and investigate its complexity by running the simulation model. In this model, CWM can be simulated via the following four iterative steps: (1) model description (identification of variables); (2) development of a casual loop diagram; (3) development of a stock-flow diagram; and (4) model test and validation [39]. To identify the variables, a comprehensive literature review was conducted. After identifying all effective variables (see Table 2), a causal loop diagram was developed as a conceptual model to simplify the complexity of the system and explicate the interrelationships among different variables interacting in various feedback loops. Usually it is better to derive a stock-flow diagram from a causal loop diagram; otherwise, the complexity of the system can cause deviation in the research procedure. A stock-flow must be simulated to dynamically calculate the mathematical equations. A pilot test should be conducted to ensure the reliability and rationality of the model [39]. Finally, the complete model can be operated with a base scenario and three subordinate scenarios to show the dynamic behavior of the system under different policies. These steps should follow a cyclic process, and in some variables, formulas, or even initial values, may be revised to make the model more accurate. Eventually, this present study 
could analyze the life cycle cost-benefits of a BIM-based construction waste chain and CWM process during a project life cycle.

Table 2. System dynamic (SD) model variables and abbreviations.

\begin{tabular}{|c|c|c|}
\hline Variable & Abbreviation & Reference \\
\hline $\begin{array}{l}\text { 3D Building information modeling (BIM) visualization } \\
\text { services }\end{array}$ & 3BVS & Elmaraghy et al. [40] \\
\hline Average number of clashes & ANoC & Won et al. [20] \\
\hline Average number of detected clashes & ANoDC & Won et al. [20] \\
\hline $\begin{array}{c}\text { Cost-benefits of using BIM in construction waste } \\
\text { management (CWM) }\end{array}$ & CBoBIM & \\
\hline Cost-benefits of conventional CWM & CBoC & Yuan et al. [10] \\
\hline Change order requests & COR & Jalaei et al. [12] \\
\hline Data capturing potential & $\mathrm{DCP}$ & Elmaraghy et al. [40] \\
\hline Demolition cost per unit & $\mathrm{DmCu}$ & \\
\hline Deconstruction cost per unit & $\mathrm{DuCu}$ & \\
\hline Economic incentive to implement BIM & EItIB & Yuan et al. [10] \\
\hline Incentive to deconstruct elements & ItDE & Jalaei et al. [12] \\
\hline Incentive to dump illegally & ItDI & Yuan [1] \\
\hline Incentive to sort waste & ItSW & Yuan et al. [10] \\
\hline Level of detail & LOD & Cheng and Ma [41] \\
\hline Landfill charge per unit & $\mathrm{Lu}$ & \\
\hline Maintenance cost & MC & Jalaei et al. [12] \\
\hline Maintenance cost per unit & $\mathrm{MCu}$ & \\
\hline Maintenance level & ML & Arditi and Nawakorawit [42] \\
\hline Maintenance quality & MQ & Arditi and Nawakorawit [42] \\
\hline Need to strengthen regulations & NSR & Yuan [1] \\
\hline Percent of illegal dumping & pID & \\
\hline Purchase order accuracy & POA & Elmaraghy et al. [40] \\
\hline Possibility of detecting clashes & PoDC & \\
\hline Possibility of introducing unnecessary changes & PoIUC & Jalaei et al. [12] \\
\hline Percent of modular buildings elements & PoMBE & \\
\hline $\begin{array}{c}\text { Potential to reduce overall materials use through design } \\
\text { optimization }\end{array}$ & PoROM & Jalaei et al. [12] \\
\hline Percent of materials to recycle & pRecycle & \\
\hline Percent of materials to reuse & pReuse & \\
\hline Price for selling reused materials per unit & PSRu & \\
\hline Price for selling recycled materials per unit & PSRyu & \\
\hline Reuse cost & RC & Yuan et al. [10] \\
\hline Recycling cost per unit & $\mathrm{RCu}$ & \\
\hline Rate of volume reduction by building design optimization & RVRbBDO & \\
\hline Rate of waste generation from construction site activities & RWGFCSA & \\
\hline Rate of waste generation to rate of clashing elements & RWGtCE & \\
\hline Rate of Waste generation to change order requests & RWGtCOR & \\
\hline Rate of waste generation through loss and over-ordering & RWGtLOO & \\
\hline Recycling cost & RyC & Yuan et al. [10] \\
\hline Sorting cost per unit & $\mathrm{SCu}$ & \\
\hline Knowledge needs for design of deconstruction & SNiDfD & Jalaei et al. [12] \\
\hline $\begin{array}{c}\text { Time needed for stakeholders to accept the risk of } \\
\text { investment }\end{array}$ & TNSARI & Miles and Wilson [43] \\
\hline Weight of design optimization & wDO & \\
\hline Waste generation from construction process & WGC & Jalaei et al. [12] \\
\hline $\begin{array}{l}\text { Waste generation from deconstruction at the end of } \\
\text { building life }\end{array}$ & WGDc & Jalaei et al. [12] \\
\hline $\begin{array}{l}\text { Waste generation dumped to landfill at the end of building } \\
\text { life }\end{array}$ & WGDm & Yuan et al. [10] \\
\hline Waste generation from maintenance process & WGM & Jalaei et al. [12] \\
\hline Waste reduction potential in construction & WRPiC & Jalaei et al. [12] \\
\hline
\end{tabular}




\subsection{Model and Variable Descriptions}

The BIM can be employed to improve the quality, accuracy, and efficiency of construction processes by optimizing the design, choosing the appropriate materials, increasing collaboration between stakeholders, providing well services, and facilitating chronological deconstruction, ultimately reducing the RWG [8]. Each of these enhancements to current construction activities can act as a chain of prerequisites for the others to occur. For example, increasing the potential of reusability necessitates good maintenance throughout the occupation period. To facilitate an understanding of the complexity and instability of these interrelationships, imperative variables influencing construction waste reduction through using BIM were identified based on the extensive literature review (see Table 2). Economic incentive to implement BIM (EItIB) indicated the willingness of the stakeholders to employ BIM to manage CWM more effectively and sustainably [40]. The economic incentives of stakeholders could be raised with the profits occurred by selling reusable materials and reducing costs [10]. Incentives to dump illegally (ItDI) is the behavior of dumping waste in appropriate places to flout the environmental law [1]. Incentive to deconstruct elements (ItDE) is considered as the desire of stakeholders to adapt the deconstruction policy [11]. This can be affected by the potential of existing building materials' recyclability. Rate of waste generation (RWG-) encompasses various causes of waste generation during buildings' life cycles, such as clashing elements, changing orders, non-optimized design, and cast-in-place construction. This rate can be decreased by achieving improved quality of design, construction, and maintenance by implementing BIM [12]. Cost-benefits of using BIM (CBoBIM) refer to the sum of all costs and profits, such as waste collection cost, sorting cost, surface preparation cost, and finally, profits of selling salvages and materials [10]. Additionally, cost-benefits of using conventional methods $(\mathrm{CBOC})$ refers to the sum of all costs associated with a dumping waste during buildings' life cycles [10].

\subsection{Causal Loop Diagram}

The conceptual model was developed based on the effective variables identified (see Figure 1). Although this causal loop diagram is comprised of several feedback loops with different branches, the dynamic behavior of the entire system can be summarized by three main loops.

The positive feedback loop R1 refers to economic incentives that urge stakeholders to sort C\&D waste. Prioritization of sorting waste affords practitioners the opportunity to recycle and prepare waste materials for reuse in different construction areas. The surface preparation, repairing, and recycling costs can be relatively recoverable from the profits obtained by selling materials, encouraging project managers to invest BIM-based CWM to facilitate expected workflow. Thus, in this feedback loop, as greater economic profits are achieved, project managers will become more inclined to sort $C \& D$ waste.

The feedback loop R2 is the main loop comprised of several subordinate circuits with different routes that can be summarized as one unique loop. Implementing BIM can reduce the RWG that can be affected by synchronizing data between models, optimizing building design, affording 3D visualization services, and facilitating data capture at the design stage. Subsequently, synchronizing the different databases and applying all alterations will enhance collaboration between different groups of contractors and labors [44]. A lack of collaboration among multiple handlers is coupled with arbitrary changes, leading to early demolition of construction elements [45]. Thus, synchronized databases will help practitioners avoid the unpredictable change of orders. Another feature of BIM with immense influence on construction and maintenance processes is greater accessibility to comprehensive visual and numerical information [46]. This capability helps practitioners avoid the over-ordering of materials and irregular storage, both of which are causes of waste generation. Convenient access to building information allows residents and contractors to perform preventive time-based maintenance before failure occurs. Repairing and adjusting ventilation systems, pipes, doors, and windows not only increases the potential of reuse and recycling at the end of a building's life, but also avoids waste generation in the operation and maintenance. The DfD approach is recognized as the foundation of BIM-based CWM [47]. DfD is applied to enhance the flexibility of all elements, allowing them 
to be salvaged instead of crushed and discarded. The use of prefabricated elements, bolted joints, and non-toxic materials can be prioritized in the design stage in order to make deconstruction more amenable [27]. All branches in feedback loop R2 ultimately concentrate on a reduction of construction waste and connecting feedback loop R2 to R1. Construction waste reduction will spur stakeholders to invest in the BIM-based CWM method.

In negative feedback loop R3, landfill charges serve as an exterior factor, motivating project managers to illegally dump C\&D waste [10]. Illegal dumping exacerbates environmental impacts and provokes public dissatisfaction [10]. By increasing concern and environmental awareness, substantial pressure is imposed on local authorities to reinforce regulations and encourage project managers to control their construction waste generation and avoid illegal activities.

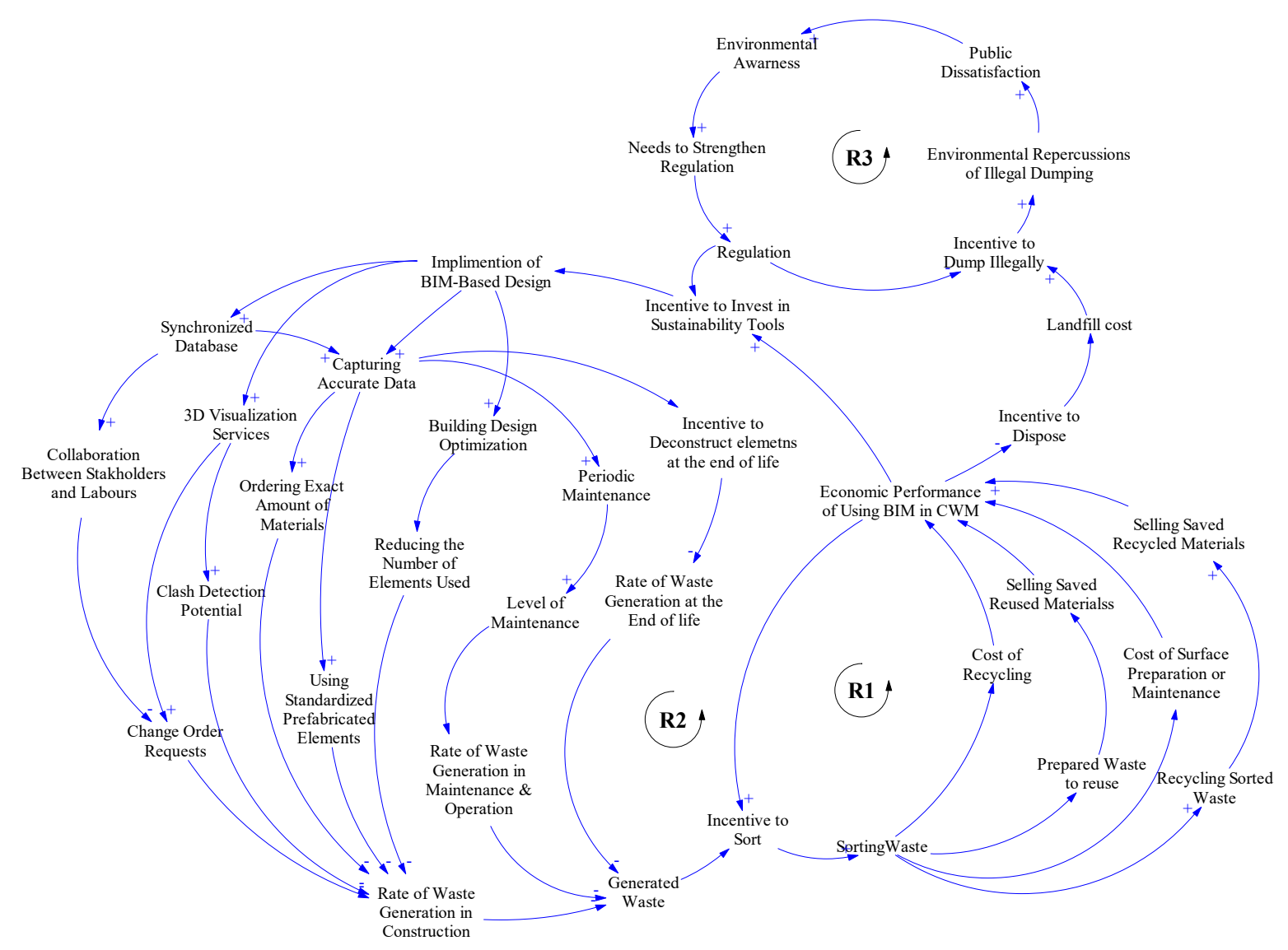

Figure 1. Causal loop diagram of life cycle cost of CWM in BIM.

\subsection{Stock-Flow Diagram}

An intelligible model of the causal loop diagram should be converted to a mathematic model. A stock-flow diagram represents a quantitative simulation of the model. Accordingly, all variables, initial values, and interrelationships must be formulated. As shown in Figure 2, a stock-flow diagram was developed in Vensim in this study.

Running the model necessitated determining logical equations between variables and adding essential details to the model, which were tabulated, as seen in Table A1 (Appendix A). It is worth mentioning that some algebraic equations and initial values were collected from the existing literature and reports published by environmental agencies, as well as predictable logical behavior [10]. Some data, such as the percentage of reuse or recycle and weight of waste generation potential waste generation were obtained from the case study project. However, initial values were intended to reflect the ratio of waste generation on an industrial scale over a long period of time. 


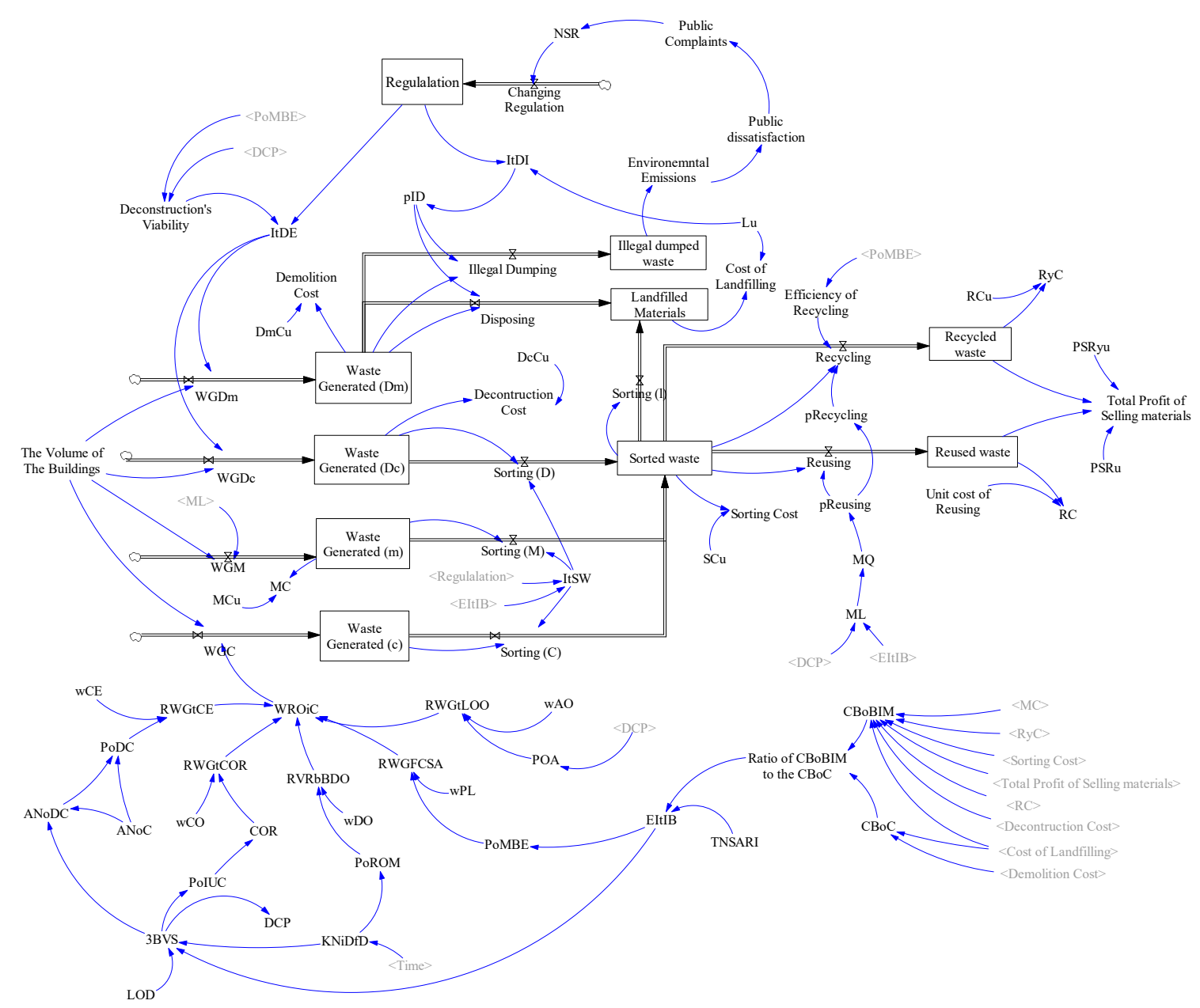

Figure 2. A stock-flow diagram of life cycle cost analysis of BIM-based CWM.

\subsection{SD Model Pilot Test}

A pilot test was conducted to test the accuracy and sensitivity of the model in this study. The sensitivity of the relationship between two primary values of the 3D model and the RWG was investigated. As illustrated in Figure 3, changing the effective variable of the 3D BIM visualization (which depends on $\mathrm{LOD}=5,4,3$, and 2) resulted in the corresponding value of the rate of waste reduction increasing significantly in the construction phase. Thus, the higher the power of the 3D model, the lower the likelihood of waste generation was. This finding is in complete accordance with previous research on the effects of using BIM-based CWM.

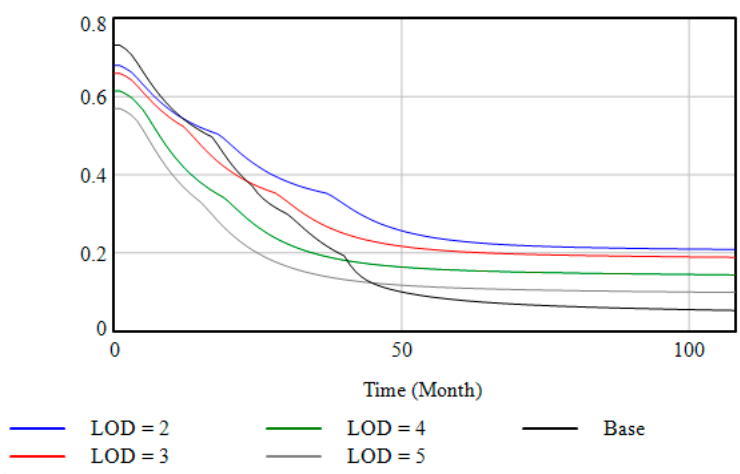

Figure 3. Model testing of RWG for $\mathrm{LOD}=5,4,3$, and 2. 


\section{Simulation Results}

After all variables and the relationships among them are confirmed by testing the model, the model simulation can be processed. Due to the larger scale of the model in this study, a total of 10 years was selected for the run to show the dynamic effects of the system. In this study, the process of changing all parameters was assumed to be modified dynamically over time in a base model scenario as to illustrate the real-world fluctuations. To highlight the roles of certain parameters, three strategies were elected to serve as scenarios.

\subsection{Running Baseline Scenario}

The first LCC benefit analysis was conducted as a baseline scenario. In the model, all variables were smoothly altered in their normal state and specific policies kept out of the system. As time progresses, project managers may desire to invest in BIM-based CWM to boost the potential of the sorting process. The adoption of BIM will lead to more profitable CWM. As Figure 4a shows, employing BIM for construction projects significantly decreased waste management costs up to $70 \%$ over conventional methods after six simulated years. Analyzing the trend of alteration in variables (i.e., incentive to invest in BIM, incentive to deconstruct, incentive to sort, and incentive to engage in illegal dumping) ranged from 0 to 1 and played an essential role in this study. Because they were considered stimuli for starting the feedback loops, these parameters obtained long-term changes from other variables. As shown in Figure $4 b$, the values of EItIB, ItDE, and ItSW all increased after six years of BIM implementation. The most obvious increase in managers' incentives up to $75 \%$ came from the desire to use prefabricated elements. A possible explanation for these results is that sorting demolished materials in poor conditions does not motivate a project manager's investment.

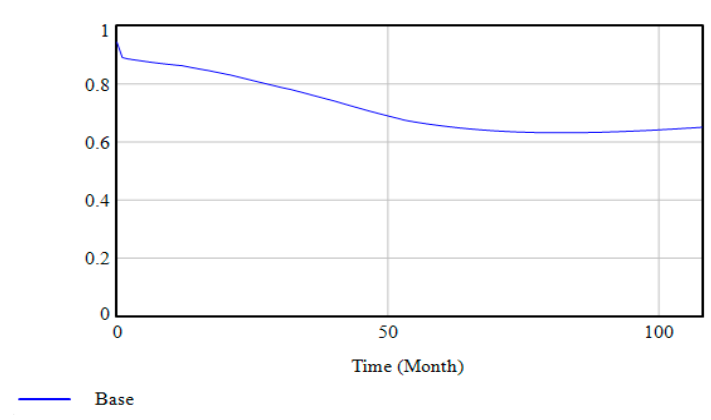

(a)

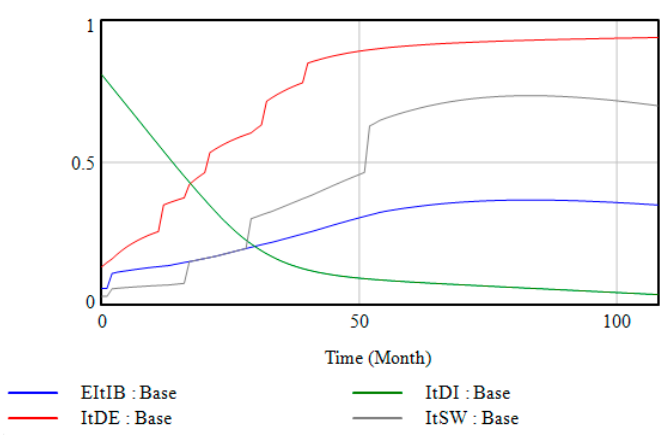

(b)

Figure 4. Simulation results of the base scenario: (a) Ratio of BIM-based CWM cost-benefits; (b) comparison of manager incentives.

Within 10 years, the adoption of BIM led to the reduction to a near-zero level of contractors' motivations to act illegally. This reduction was largely due to regulation reinforcement and consistent monitoring, as well as the increase in potential for deconstruction to serve as an alternative sustainable strategy for waste management. As demonstrated above, it was essential that this system assess the rate of change in motivation. Thus, the three scenarios encompassed the following parameters: (1) time required for stakeholders to be persuaded to accept the investment risk, (2) amount of landfill charge cost, and (3) percentage of prefabricated materials utilized in the design phase.

\subsection{Scenario A: Time Taken for Accepting the Risk of Investment}

As can be seen from the stock-flow diagram, the parameter EItIB depended on the two values of the ratio of the profit gained by BIM compared to that of non-BIM and the time needed for stakeholders to accept the risk of investment (TNSARI). Scenario A was simulated to show how variations in the latter influenced entire system 
In the base scenario simulation, the initial TNSARI value was set to 1 month, which was then increased to 1,2, 3, and 4 years to show inclusively the dynamic effects of critical factors. As the simulation results shown in Figure 6 indicate, increasing the time for stakeholders to make decisions imposes a significant delay on the whole system. Putting off further investment in BIM by approximately four years represented a 15\% diminution in profit obtained over the baseline scenario. An increase in TNSARI value decreased the overall construction waste reduction to such an extent that after six simulated years, the percentage of waste generation was reduced by only about $40 \%$, which was achieved in the first months of the baseline scenario (see Figure 5). Despite the fact that incurring risk is intrinsic to investment decisions, to a large extent this scenario explains the importance of research in this field in order to convince stakeholders to invest in BIM-based CWM at early design stages.

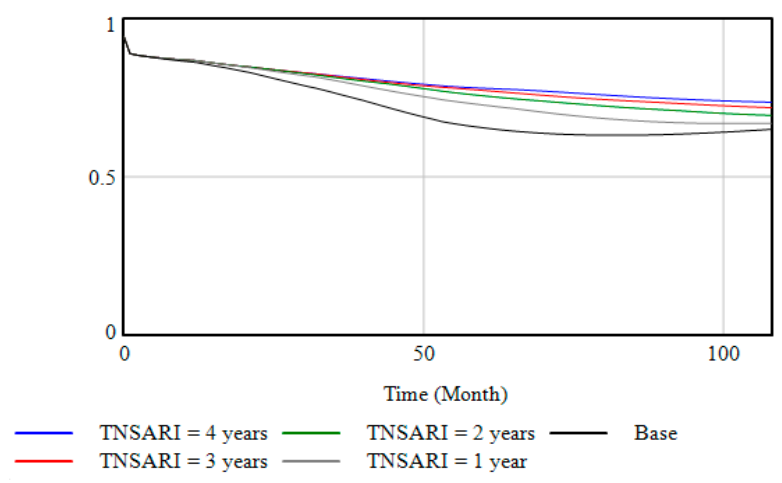

Figure 5. Simulation results of Scenario A: Ratio of CBOoBIM to CBoC under different TNSARI values.

\subsection{Scenario B: Percentage of Modular Building Elements}

The high capital cost of adopting prefabricated elements serves as a barrier, causing it to frequently be ruled out by stakeholders. Thus, in the baseline scenario, the percentage of prefabricated elements utilized increased over time as the economic incentive was enhanced. In Scenario B, the percentage of modular elements used in construction was scaled from 0 to 100 in order to demonstrate the impact of this variable on reducing waste management cost. This value was increased to 35, 55, 75, and 95 to examine the dynamic variation of the intended parameters. As can be seen in Figure 6a, with an increase in the percentage of modular components used, waste generation dropped sharply by about $35 \%$. The waste generation rate in the baseline scenario declined smoothly from $75 \%$ to less than $10 \%$, showing the dynamic behavior of all variables over time. Moreover, increasing the value of PoMBE to $90 \%$ diminished the amount of CWM cost by $27 \%$ more than what was seen in the baseline at the maximum possible amount seen in the sixth year (see Figure 6b).

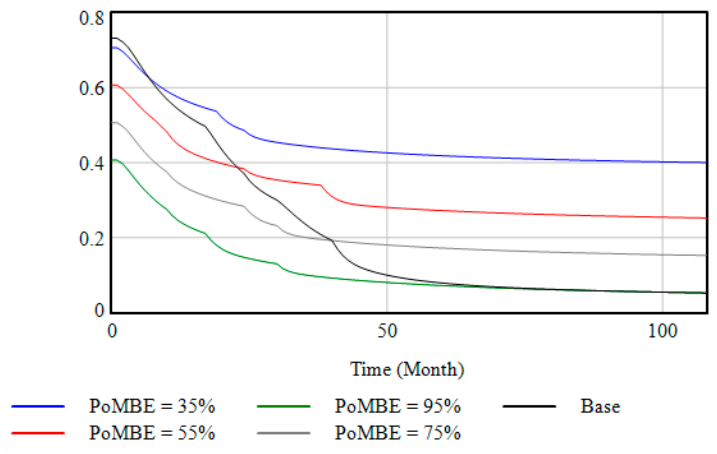

(a)

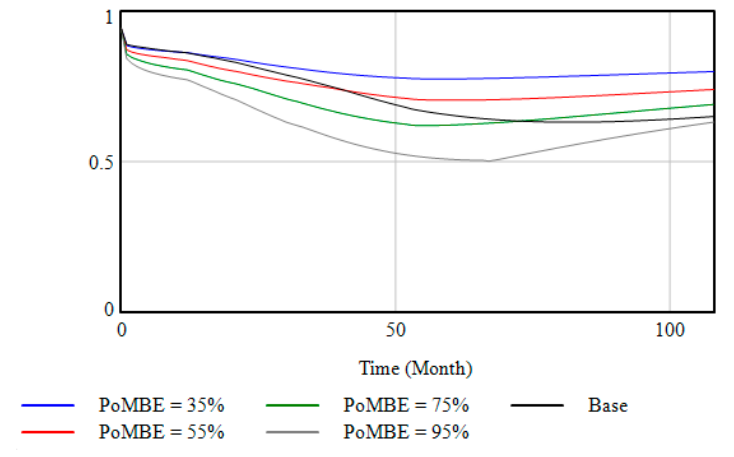

(b)

Figure 6. Simulation result for Scenario B: (a) RWG under different PoMBE; (b) ratio of CBoBIM to $\mathrm{CBoC}$. 


\subsection{Scenario C: Landfill Charge}

In Scenario C, increasing the landfill charge reduced in a gentle slope the incentive to legally use a landfill. Figure 7a shows that under the four charging schemes (ranging from $\$ 120$ to $\$ 180$ ), a reluctance to legally dispose of waste emerged as project managers preferred to take the risk and flout the law. Although the incentive to dump illegally did not decrease as sharply as the baseline scenario, it was reduced. The reason for the total amount of decline was that only a fraction of the waste was entered in this phase, and there were some project managers who preferred to choose sustainable deconstruction over landfilling or illegal dumping. As can be seen in Figure 7a, the schemes' lines were very close in the first months of the project duration because of the delay in discharging environmental emissions from illegally dumped waste; subsequently, dissatisfaction emerged. In addition, the ratio of the CWM cost of BIM approach to that of a non-BIM approach did not sufficiently decline. It can be concluded that fewer project managers decided that illegally dumping waste would be preferable (see Figure $7 \mathrm{~b}$ ).

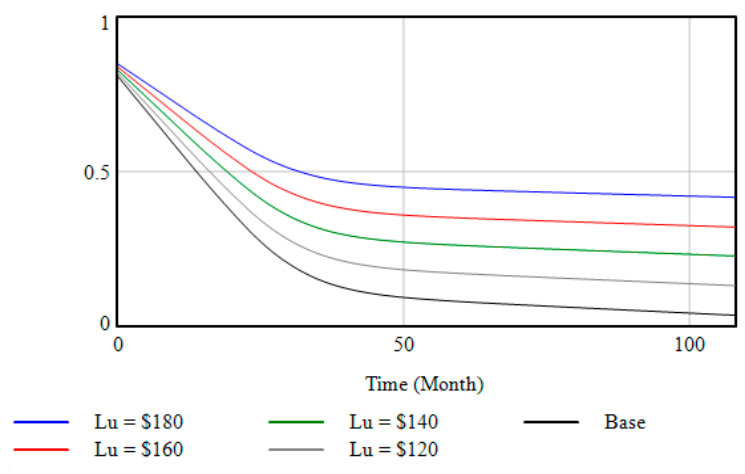

(a)

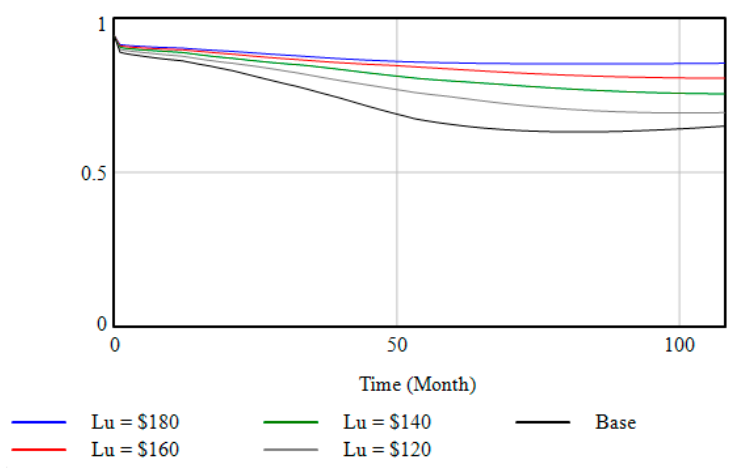

(b)

Figure 7. Simulation results for Scenario C: (a) ItDI under different landfill charge; (b) ratio of CBoBIM to CBoC.

\section{Case Study Validation}

Since the variables inputted as initial values in the SD model were assumed to reflect an industrial scale, it was judicious to evaluate the system with a case project. A 12-story commercial building project in the city of Montreal, Canada, with an area of $11,850 \mathrm{~m}^{2}\left(127,552.215 \mathrm{ft}^{2}\right)$ was examined as a case project in the present research. This building project employed the conventional CWM method. Based on the BIM-based CWM, designers tried to employ DfD approaches to redesigning the structure by replacing some unrecyclable components with modular elements. The LCC of BIM-based CWM and non-BIM methods were analyzed and compared. Table 3 lists the deconstruction, surface preparation, and recycling process costs, as well as the profits obtained from selling reused materials as determined by applying a BIM-based approach at the last phase of the building life cycle. Demolition and landfill costs were considered conventional methods of CWM. Transportation and collection cost were disregarded in this research due to the variety of distances and trucks. The unit cost of each process was obtained from the RS means.

As described in Table 3, the deconstruction cost was far higher than the demolition cost, because deconstruction processes are time-consuming and require craftsmen to separate each element. However, the additional cost of deconstruction can be mitigated by the resale of the material saved. According to the results, the total cost-benefit of demolition waste management at the end of a building's life span was $16.2 \%$ of the conventional CWM. The CWM costs in the maintenance and construction phase are described in Table 4. CWM cost in the construction phase encompasses the cost of collecting useless materials onsite and landfill costs. In some areas (e.g., clashing elements), materials may not be matched with new designs and must be changed. These elements can also be separated from their platforms to be sold at lower prices. 
Table 3. Life cycle cost analysis: Comparison of BIM-based CWM and conventional CWM in building life close (Unit \$).

\begin{tabular}{|c|c|c|c|c|c|c|c|c|c|}
\hline \multirow{2}{*}{$\begin{array}{l}\text { Material } \\
\text { (unit) }\end{array}$} & \multicolumn{5}{|c|}{ BIM-Based CWM in Building Close } & \multicolumn{4}{|c|}{ Conventional CWM in Building Close } \\
\hline & $\begin{array}{l}\text { Recycling } \\
\text { Cost (A) }\end{array}$ & $\begin{array}{l}\text { Deconstruction } \\
\text { Cost (B) }\end{array}$ & $\begin{array}{l}\text { Landfill Cost } \\
\text { (C) }\end{array}$ & $\begin{array}{l}\text { Profit from } \\
\text { Selling (D) }\end{array}$ & $\begin{array}{c}\text { Profit E } \\
(D-(A+B+C))\end{array}$ & $\begin{array}{l}\text { Demolition } \\
\text { Cost (B) }\end{array}$ & $\begin{array}{c}\text { Landfill } \\
\text { Charge (C) }\end{array}$ & $\begin{array}{l}\text { Profit from } \\
\text { Selling (D) }\end{array}$ & $\begin{array}{c}\text { Profit E } \\
(D-(B+C))\end{array}$ \\
\hline Concrete $\left(\mathrm{m}^{3}\right)$ & $133,320.86$ & $90,901.66$ & $57,951.88$ & $19,490.96$ & $-262,683.00$ & $58,924.14$ & $260,783.50$ & & $-319,708.00$ \\
\hline Rebar (ton) & & 568.87 & 90.98 & 2924.50 & 2264.64 & & 2843.26 & 4061.80 & 1218.54 \\
\hline Structure metal (ton) & & $144,357.19$ & 4042.00 & $424,410.15$ & $276,011.00$ & $92,499.65$ & 5285.69 & $184,999.30$ & $87,213.96$ \\
\hline Gypsum (ton) & $18,058.09$ & $159,706.39$ & 2223.12 & $231,522.17$ & $51,534.56$ & 1261.94 & $41,846.98$ & & $-43,108.90$ \\
\hline Door wood $\left(\right.$ Ea. $\left./ \mathrm{m}^{2}\right)$ & $14,231.16$ & $16,946.00$ & 8679.55 & $110,216.61$ & $70,359.88$ & 7694.40 & & 1822.33 & -5872.06 \\
\hline Door aluminum $\left(\mathrm{m}^{2} / \mathrm{m}^{3}\right)$ & 2476.60 & 2405.00 & 272.50 & $11,700.00$ & 6545.88 & 1092.00 & 2725.06 & & -3817.07 \\
\hline Window $\left(\mathrm{m}^{2}\right)$ & 83.76 & 333.00 & 9.67 & 364.5 & -61.94 & 188.75 & 96.76 & & -285.52 \\
\hline window (Ea.) & 4504.18 & $16,650.00$ & 2979.70 & $16,200.00$ & -7933.89 & & & & \\
\hline Clay ceramic $\left(\mathrm{m}^{2}\right)$ & 52.29 & $43,156.68$ & & & $-43,209.00$ & $43,156.68$ & $34,941.80$ & & $-78,098.50$ \\
\hline Pipes (m) & & 5321.08 & & & -5321.09 & & & & \\
\hline Plumbing (Ea.) & $10,018.50$ & $30,000.00$ & 4.48 & $57,375.00$ & $17,352.01$ & $63,750.00$ & 44.89 & & $-63,794.90$ \\
\hline Cabinet (Ea. $\left./ \mathrm{m}^{2}\right)$ & $15,627.89$ & 3834.00 & 1036.61 & 9720.00 & $-10,778.50$ & 3834.00 & $10,366.18$ & & $-14,200.20$ \\
\hline Lighting fixture & & $79,317.09$ & 6.79 & 7866.00 & $-71,457.90$ & & 67.94 & & -67.94 \\
\hline Railing (m) & 718.50 & 866.14 & & 4063.50 & 2478.85 & 866.14 & & 135.00 & -731.14 \\
\hline Ducts (ton) & & $94,783.61$ & & $62,040.18$ & $-32,743.40$ & $94,783.61$ & $10,943.65$ & & $-105,727.00$ \\
\hline Blue stone $\left(\mathrm{m}^{2}\right)$ & 4036.80 & 7297.86 & $24,234.67$ & $70,991.14$ & $35,421.80$ & 7297.86 & $242,346.70$ & & $-249,645.00$ \\
\hline Brick $\left(\mathrm{m}^{2}\right)$ & $23,625.72$ & $294,207.10$ & 4940.84 & $113,974.86$ & $-208,799.00$ & $226,398.43$ & $49,408.48$ & & $-275,807.00$ \\
\hline Total & $226,754.39$ & $990,651.72$ & $106,472.90$ & $1,142,859.60$ & $-181,019.00$ & $631,544.67$ & $676,563.40$ & $191,018.44$ & $-1,117,089.70$ \\
\hline
\end{tabular}


Table 4. Life cycle cost analysis: Comparison of BIM-based CWM and conventional CWM in maintenance and construction phases (Unit: \$).

\begin{tabular}{|c|c|c|c|c|c|c|c|c|}
\hline \multirow{3}{*}{ Material (Unit) } & \multicolumn{4}{|c|}{ Construction Phase } & \multicolumn{4}{|c|}{ Maintenance and Operation Phase } \\
\hline & \multicolumn{3}{|c|}{ Non-BIM } & \multirow{2}{*}{$\begin{array}{c}\text { BIM } \\
\begin{array}{c}\text { Construction } \\
\text { Waste Cost }\end{array}\end{array}$} & \multicolumn{2}{|c|}{ Non-BIM } & \multicolumn{2}{|c|}{ BIM } \\
\hline & $\begin{array}{l}\text { CWM } \\
\text { Cost }\end{array}$ & $\begin{array}{c}\text { Clash } \\
\text { Detection }\end{array}$ & $\begin{array}{l}\text { Change } \\
\text { Order }\end{array}$ & & $\begin{array}{c}\text { Maintenance } \\
\text { Cost }\end{array}$ & $\begin{array}{l}\text { Average Life } \\
\text { Time }\end{array}$ & $\begin{array}{c}\text { Maintenance } \\
\text { Cost }\end{array}$ & $\begin{array}{c}\text { Average Life } \\
\text { Time }\end{array}$ \\
\hline Concrete $\left(\mathrm{m}^{3}\right)$ & $-28,975.93$ & & -3.18 & & & & & \\
\hline Rebar (ton) & -121.85 & & & & & & & \\
\hline Structure metal (ton) & -5663.24 & & & & & & & \\
\hline Gypsum (ton) & -418.46 & & -4163.65 & -222.31 & $-27,224.45$ & 75 & $-23,673.43$ & 25 \\
\hline Door wood (Ea./m²) & & & & & & & $-35,577.92$ & 30 \\
\hline Door aluminum $\left(\mathrm{m}^{2} / \mathrm{m}^{3}\right)$ & & & & & & & -6191.51 & 30 \\
\hline Window $\left(\mathrm{m}^{2}\right)$ & & & & & & & -209.41 & 30 \\
\hline window (Ea.) & & & & & & 33 & -559.72 & 30 \\
\hline Clay ceramic $\left(\mathrm{m}^{2}\right)$ & -655.15 & & & & & & $-118,291.07$ & 50 \\
\hline Pipes (m) & & -493.26 & & & & & & \\
\hline Plumbing (Ea.) & & & & & $-15,155.28$ & 25 & $-29,144.76$ & 13 \\
\hline Cabinet $\left(\right.$ Ea. $\left./ \mathrm{m}^{2}\right)$ & & & & & & & $-10,797.38$ & 38 \\
\hline Lighting fixture & -0.67 & & & & & & $-39,761.25$ & 38 \\
\hline \multicolumn{9}{|l|}{ Railing (m) } \\
\hline Ducts (ton) & -109.43 & $-19,455.4$ & & & & & & \\
\hline Blue stone $\left(\mathrm{m}^{2}\right)$ & & & & & $-45,018.75$ & 30 & $-105,133$ & 10 \\
\hline $\operatorname{Brick}\left(\mathrm{m}^{2}\right)$ & $-12,117.33$ & & -721.27 & & & & & \\
\hline Concrete $\left(\mathrm{m}^{3}\right)$ & 2470.42 & & -8847.76 & & & & & \\
\hline Total & $-45,591.69$ & $-19,948.7$ & $-13,735.9$ & -222.31 & $-87,398.48$ & & $-369,339.48$ & \\
\hline
\end{tabular}


The cost of CWM in the maintenance phase also includes the periodic services and inspections that keep facilities in good condition during the operations life cycle. Buildings in good condition serve as motivation for managers to invest in repair or recycling processes instead of sending remaining materials to a landfill. According to Table 4, the maintenance cost from the BIM-based CWM approach was much higher than for the non-BIM method owing to several time-based services. Table 5 illustrates a comparison of every project's CWM expenses and profits obtained from these two different methods. The total recycling and preparation costs refer to the costs of proper surface preparation required to clean and process materials after deconstruction. The case study did not consider about the reuse of salvaged materials; thus, the cost for recycling and preparation was not considered. Generally, the materials can be damaged or broken during demolition, and only small portion of salvaged materials can be reusable [40]. BIM-based CWM needs approximately 137\% demolition cost compared with the conventional CWM cost due to additional labor and machinery costs [48]. More labors and equipment are often being employed to prevent material contamination and minimize the damage to the elements dismantled [48]. Additionally, total maintenance costs in the BIM-enabled method was computed about 4.7 times higher than the reported cost for traditional CWM in the operation and maintenance phase. The case project did not report about the cost of waste during the construction step; on the other hand, the SD model reported \$222.31 in the same phase. According to this case study, some materials, which could not be recycled had to be dumped in a landfill. BIM-based CWM could significantly reduce landfill costs by about $85 \%$ compared with the non-BIM method based on the SD model simulation. Therefore, a total life cycle cost for this building based on the BIM-implemented CWM was higher than the conventional one by about 1.15 times. Although the final life cycle cost in the case of BIM-based CWM is higher than the cost of the non-BIM method, the total cost-benefits after selling can be reduced by up to $57 \%$ if the BIM-based CWM method is implemented. This is if the expenses can be mostly offset by the sale of salvaged materials at the end of the building's life cycle. The profits from selling were recorded at $\$ 1,142,860.00$ for the BIM-based method and $\$ 191,018.40$ for traditional CWM.

Table 5. Total cost-benefit analysis of CWM using BIM and non-BIM methods.

\begin{tabular}{ccc}
\hline Cost Descriptions (Units: \$) & BIM-Based CWM & Conventional CWM \\
\hline Total recycling and preparation Cost (A) & $-226,754.40$ & $-631,544.70$ \\
Total deconstruction cost (B) & $-990,651.70$ & $-676,563.40$ \\
Total landfill cost (C) & $-106,472.90$ & $-79,276.29$ \\
Total waste cost during construction (D) & -222.31 & $-1,474,782.87$ \\
Total maintenance cost (E) & -369.339 .48 & $191,018.40$ \\
Total life cycle cost (F = A + B + C + D +E) & $-1,693,440.79$ & $-1,283,764.47$ \\
Profit from selling (G) & $1,142,860.00$ & -10.06 \\
Total cost after selling (H = G + F) & $-550,580.79$ & \\
Total cost per Square Foot (\$/S.F.) & -4.32 & $0.57(57 \%)$ \\
Percent of cost savings & &
\end{tabular}

\section{Discussion}

Based on the developed SD model and the results of the case study in this study, it can be concluded that using BIM can help to significantly reduce the CWM cost on a building's life cycle. The SD model provided the insight about the impacts of different effective variables and their interrelationships. The findings of this study have noteworthy implications to the body of literature and practice as follows:

First, dynamic modeling of BIM-integrated CWM indicated the needs of a BIM-based sustainable CWM method for the stakeholders during the building's life cycle, including design, construction, operation, and maintenance, and by the end of the building life. The results of simulation showed the willingness of stakeholders to accept more sustainable approaches to reduce CWM costs by up to $40 \%$ (Figure $4 \mathrm{a}$ ). The result of this study encourages them to implement the BIM into the CWM approach. Second, the BIM-based CWM approach can lead to better decision-making in material 
sorting and deconstruction procedures based on the SD model simulation in this study. By adapting the method (increased rate of using sustainable tools in the SD model), managers tend to behave more legally in dumping during the deconstruction process (decreasing the rate of incentives for illegal dumping in the model). Additionally, based on the scenario analysis, the results showed that increased landfill charges without having the relevant regulations and effective infrastructures established was not effective to reduce waste generation and the likelihood of illegal activities in waste dumping during the project life cycle. This indicates properly that BIM integration is considerable to the current CWM, but it still requires the support of government to establish more proper regulations and infrastructures. Eventually it can ultimately help to reduce waste generations and illegal activities during deconstruction. Third, it showed that reducing the time for consideration to accept the risks would help to accelerate the rate of waste reduction in the model. In addition, this model also predicted that the increased rate of prefabrication use can lead to a reduced rate of waste generation by about 70\% (see Figure 6a). Additionally, the BIM-integrated approach can significantly help to reduce the landfill and increase the possibility of reusing waste based on the simulation (Table 5). Therefore, it implies that this SD model can also serve as a guideline to predict the applicability and feasibility of BIM-enabled CWM. Additionally, the proposed model can support the multifaceted decision-making with both short- and long-term perspectives to the use of BIM in the CWM.

In the case study validation, it was revealed that the cost for deconstruction and total maintenance was significantly higher than that of the conventional method. However, the BIM can manage the numerous information about detailed conditions of building systems, construction processes, and material. As a result, the BIM-based method could provide significant savings from the landfill charges and from selling the salvaged materials (Table 5). With significant cost savings from the use of BIM in the case study, the results made a substantial contribution to better understanding of the potential of BIM-based CWM for the body of knowledge and practice. For further study, it is recommended that the needs of social impacts and performance of the BIM-based CWM can be assessed by extending the current SD model developed in this study.

\section{Conclusions}

In this research, the economic efficiency and usefulness of using BIM-based CWM were investigated and quantified through the SD approach. Despite the fact that previous studies have proposed various CWM methods, they are not being used as often as expected due to the lack of quantitative economic benchmarks. Moreover, the studies were carried out from a static point of view, leading researchers to overlook the dynamic nature of essential variables and embedded relationships. In this regard, the novelty of the present study is twofold: quantifying cost-benefits of using BIM for CWM throughout a building's life span and employing an SD approach to consider all variations and dynamically simulate the waste chain from an industrial scale.

To better understand the complexity of the type of system, causal loop and stock-flow diagrams were developed. A sensitivity test was conducted to verify the accuracy of the model. These simulation results elucidated the increasing economic motivation for investors to employ BIM as a sustainable method of CWM during the project life cycle. Increasing the BIM uses will enhance the collaboration among stakeholders, optimize data capture, and boost the potential for visualization. In turn, this will enhance the quality and accuracy of design and construction, help managers alleviate different causes of waste generation, such as clashing structural and mechanical elements, prevent over-ordering of raw materials, minimize damage occurring during delivery, and reduce the need to order non-standard sizes of modules. Equipped with information about electrical and mechanical systems that is required during the operation, stakeholders can provide periodic maintenance services that decrease depreciation expenses. This study tested different scenarios to demonstrate the effects of each variable. Increasing landfill charges also increases the tendency to engage in illegal dumping, showing that increasing landfill costs will not encourage project managers to invest in more sustainable methods. Conversely, the more prefabricated elements are used, the greater the potential for reuse and recycling of materials. 
Consequently, applying prefabricated materials in the design and construction phases and complying with BIM-based design rules will increase the potential benefits and reduce related costs.

A 12-story commercial building was employed as a case study in this study. A cost-benefit analysis of BIM-based CWM was compared to the conventional CWM. The results show that cost can be reduced by up to $57 \%$. The results also indicate that selling recyclable and reusable materials at the end of a building life span will approximately mitigate deconstruction cost, which are much higher than the price of conventional demolition. In this case, BIM-based CWM expenses at the end of a building life cycle are $16 \%$ of the demolition costs incurred when using conventional CWM methods. This study analyzed the cost-benefits of using BIM-based CWM by using an SD approach. This study contributes to better understanding of construction waste prevention by using the BIM and predicting the economic benefits of BIM implementation in the CWM procedure. Based on the identified variables and the proposed SD model, further studies can assess the social performance of using BIM in CWM procedures and analyze the efficiency of human resource management in the BIM-based CWM.

Author Contributions: Conceptualization, M.Z. and S.K.; Data curation, M.Z.; Formal analysis M.Z. and S.K.; Methodology, M.Z. and S.K.; Project administration, S.K.; Software, M.Z. and S.K.; Supervision, S.K.; Validation, M.Z.; Visualization, M.Z.; Writing—original draft, M.Z.; Writing—review and editing, S.K. All authors have read and agreed to the published version of the manuscript.

Funding: The APC was funded by the Office of Research and Economic Development (ORED) in the University of Alabama (Project \#: AP19-0225).

Conflicts of Interest: The authors declare no conflict of interest.

\section{Appendix A}

Table A1. Mathematical equations of identified parameters.

\begin{tabular}{|c|c|}
\hline Parameters & Equations \\
\hline EItIB & SMOOTH(1-Ratio of CBoBIM to the CBoC, TNSARI) \\
\hline Ratio of CBoBIM to the $\mathrm{CBoC}$ & $1-\mathrm{CBoBIM} / \mathrm{CBoC}$ \\
\hline PoMBE & $\begin{array}{c}\text { DELAY1( IF THEN ELSE(EItIB }<=0.2, \text { IF THEN ELSE(EItIB }<=0.15, \text { IF } \\
\text { THEN ELSE( EItIB }<=0.1,30,50), 75), 95), 10)\end{array}$ \\
\hline RWGFCSA & $(1-\mathrm{PoMBE} / 100) \times w \mathrm{wL}$ \\
\hline ANoDC & $\begin{array}{c}\text { IF THEN ELSE("3BVS" }<=80, \text { IF THEN ELSE( } " 3 B V S "<=65, \text { IF THEN } \\
\text { ELSE("3BVS" }<=50,0.5 \times \text { ANoC, } \\
0.65 \times \text { ANoC), } 0.8 \times \text { ANoC), ANoC) }\end{array}$ \\
\hline CBoBIM & $\begin{array}{c}\text { (+Sorting Cost }+\mathrm{RC}+\mathrm{RyC}+\text { Deconstruction Cost }+0.05 \times \text { Cost of } \\
\text { Landfilling }+\mathrm{MC}-\text { Total Profit of Selling materials) }\end{array}$ \\
\hline CBoC & $(0.95 \times$ Cost of Landfilling + Demolition Cost $)$ \\
\hline Changing regulation & $\begin{array}{l}\text { SMOOTH( IF THEN ELSE(NSR }<=80 \text {, IF THEN ELSE(NSR }<=60, \text { IF } \\
\text { THEN ELSE(NSR }<=40 \text {, IF THEN ELSE(NSR }<=20,1,5), 20), 20), 25), 6 \text { ) }\end{array}$ \\
\hline Cost of landfilling & Lu $\times$ Landfilled Materials \\
\hline Deconstruction viability & $(\mathrm{DCP}+\mathrm{PoMBE}) / 2 \times 0.01$ \\
\hline Deconstruction cost & $\mathrm{DcCu} \times$ "Waste Generated (Dc)" \\
\hline Demolition cost & $\mathrm{DmCu} \times$ "Waste Generated $(\mathrm{Dm}) "$ \\
\hline Disposing & $(\mathrm{pID}) \times$ "Waste Generated $(\mathrm{Dm}) " \times 0.005$ \\
\hline $\mathrm{DmCu}$ & 4 \\
\hline Efficiency of recycling & PoMBE $\times 0.01$ \\
\hline EItIB & SMOOTH(1 - Ratio of CBoBIM to the CBoC, TNSARI) \\
\hline Environmental emissions & DELAY1( Illegal dumped waste, 24) \\
\hline
\end{tabular}


Table A1. Cont.

\begin{tabular}{|c|c|}
\hline Parameters & Equations \\
\hline FINAL TIME & 108 \\
\hline Illegal dumped waste & Initial value: 1000 \\
\hline Illegal dumping & MAX $($ pID $\times$ "Waste Generated $(\mathrm{Dm}) " \times 0.005,50)$ \\
\hline ItDE & $\begin{array}{c}\text { IF THEN ELSE(Regulation }<=80, \text { IF THEN ELSE(Regulation }<=60 \text {, IF } \\
\text { THEN ELSE(Regulation }<=40,0.6 \times \text { Deconstruction Viability, } 0.8 \times \\
\text { Deconstruction Viability) } 0.9 \times \text { Deconstruction Viability) } \\
\text { Deconstruction Viability) }\end{array}$ \\
\hline ItDI & $\begin{array}{c}\text { IF THEN ELSE }(\mathrm{Lu}<=180 \text {,IF THEN ELSE }(\mathrm{Lu}<=160, \text { IF THEN ELSE }(\mathrm{Lu} \\
<=140, \text { IF THEN ELSE }(\mathrm{Lu}<=120, \text { IF THEN ELSE }(\mathrm{Lu}<=100,(90-0.9 \times \\
\text { Regulation }) \times 0.01,(90-0.8 \times \text { Regulation }) \times 0.01),(90-0.7 \times \text { Regulation }) \\
\times 0.01),(90-0.6 \times \text { Regulation }) \times 0.01),(90-0.5 \times \text { Regulation }) \times 0.01), \\
(90-0.4 \times \text { Regulation }) \times 0.01)\end{array}$ \\
\hline ItSW & $\begin{array}{c}\text { IF THEN ELSE(Regulation }<=90 \text {, IF THEN ELSE(Regulation }<=75 \text {, IF } \\
\text { THEN ELSE(Regulation }<=50,0.5 \times \text { EItIB }, 1 \times \text { EItIB) }, 1.5 \times \text { EItIB) }, 2 \times \\
\text { EItIB) }\end{array}$ \\
\hline KNiDfD & $100-(80 /(0.1 \times$ Time +1$))$ \\
\hline Landfilled materials & Disposing + "Sorting (l)" \\
\hline $\mathrm{Lu}$ & 180 \\
\hline MC & MCu × "Waste Generated $(\mathrm{m}) "$ \\
\hline $\mathrm{MCu}$ & 125 \\
\hline ML & DELAY3( $(0.01 * \mathrm{DCP}+\mathrm{EItIB}) / 2,10)$ \\
\hline MQ & $\begin{array}{c}\text { IF THEN ELSE(ML }<=0.5, \text { IF THEN ELSE(ML }<=0.4, \text { IF THEN } \\
\text { ELSE(ML }<=0.3, \text { IF THEN ELSE(ML }<=0.15,0.05,0.15), 0.25), 0.35), 0.4)\end{array}$ \\
\hline NSR & SMOOTH3I(Public Complaints, 10, 90) \\
\hline pID & ItDI $\times 100$ \\
\hline POA & $\mathrm{DCP} \times 0.01$ \\
\hline PoDC & ANoDC/ANoC \\
\hline PoIUC & SMOOTH( 100 - "3BVS", 2) \\
\hline PoMBE & $\begin{array}{c}\text { DELAY1( IF THEN ELSE(EItIB }<=0.2, \text { IF THEN ELSE(EItIB }<=0.15, \text { IF } \\
\text { THEN ELSE( EItIB }<=0.1,30,50), 75), 95), 10)\end{array}$ \\
\hline PoROM & KNiDfD/100 \\
\hline pRecycling & $0.96-$ pReusing \\
\hline pReusing & $\begin{array}{l}\text { IF THEN ELSE(MQ }<=5 \text {, IF THEN ELSE(MQ }<=4 \text {, IF THEN ELSE(MQ } \\
\quad<=3 \text {, IF THEN ELSE(MQ }<=2,0.05,0.15), 0.25), 0.35), 0.4)\end{array}$ \\
\hline PSRu & 150 \\
\hline PSRyu & 100 \\
\hline Public complaints & $\begin{array}{c}\text { IF THEN ELSE(Public dissatisfaction }<=0.6 \text {, IF THEN ELSE( Public } \\
\text { dissatisfaction }<=0.45 \text {, IF THEN ELSE(Public dissatisfaction }<=0.3 \text {, IF } \\
\text { THEN ELSE(Public dissatisfaction }<=0.2 \text {, IF THEN ELSE(Public } \\
\text { dissatisfaction }<=0.1,10,20), 35), 50), 65), 80 \text { ) }\end{array}$ \\
\hline Public dissatisfaction & SMOOTH3( TREND(Environmental Emissions, 1, 1),4) \\
\hline Ratio of CBoBIM to the $\mathrm{CBoC}$ & $1-\mathrm{CBoBIM} / \mathrm{CBoC}$ \\
\hline $\mathrm{RC}$ & Unit cost of Reusing $\times$ Reused waste \\
\hline $\mathrm{RCu}$ & 90 \\
\hline Recycled waste & Recycling \\
\hline Recycling & Sorted waste $\times$ Efficiency of Recycling $\times$ pRecycling \\
\hline Regulation & SMOOTH( Changing Regulation $\times 0.1,6)$ \\
\hline
\end{tabular}


Table A1. Cont.

\begin{tabular}{|c|c|}
\hline Parameters & Equations \\
\hline Reusing & Sorted waste $\times$ pReusing \\
\hline RVRbBDO & $\mathrm{wDO} \times(1-\mathrm{PoROM})$ \\
\hline RWGFCSA & $(1-\mathrm{PoMBE} / 100) \times \mathrm{wPL}$ \\
\hline RWGtCE & $(1-\mathrm{PoDC}) \times w C E$ \\
\hline RWGtCOR & $\mathrm{wCO} \times \mathrm{COR}$ \\
\hline RWGtLOO & $\mathrm{wAO} \times(1-\mathrm{POA})$ \\
\hline $\mathrm{RyC}$ & Recycled waste $\times \mathrm{RCu}$ \\
\hline $\mathrm{SCu}$ & 30 \\
\hline Sorted waste & $\begin{array}{c}\text { "Sorting (C)" + "Sorting (D)" + "Sorting (M)" - Recycling - Reusing - } \\
\text { "Sorting (l)" }\end{array}$ \\
\hline "Sorting (C)" & ItSW $\times$ "Waste Generated $(\mathrm{c}) " \times 0.01$ \\
\hline "Sorting (D)" & ItSW $\times$ "Waste Generated $(\mathrm{Dc}) " \times 0.01$ \\
\hline "Sorting (l)" & Sorted waste $\times 0.04$ \\
\hline "Sorting (M)" & "Waste Generated $(\mathrm{m}) " \times$ ItSW $\times 0.01$ \\
\hline Sorting Cost & Sorted waste $\times \mathrm{SCu}$ \\
\hline The volume of the buildings & 10,000 \\
\hline Total profit of selling materials & Recycled waste $\times$ PSRyu + PSRu $\times$ Reused waste \\
\hline wAO & 10 \\
\hline Unit cost of reusing & 70 \\
\hline "Waste generated (c)" & WGC - "Sorting (C)" \\
\hline "Waste generated (Dc)" & WGDc - "Sorting (D)" \\
\hline "Waste generated (Dm)" & WGDm - Disposing-Illegal Dumping \\
\hline "Waste generated (m)" & WGM - "Sorting (M)" \\
\hline wCE & 10 \\
\hline wCO & 10 \\
\hline wDO & 20 \\
\hline WGC & The Volume of The Buildings $\times 0.1 \times \mathrm{WROiC}$ \\
\hline WGDc & The Volume of The Buildings $\times$ ItDE \\
\hline WGDm & The Volume of The Buildings $\times(1-$ ItDE $)$ \\
\hline WGM & $(1-\mathrm{ML}) \times$ The Volume of The Buildings $\times 0.01$ \\
\hline $\mathrm{wPL}$ & 50 \\
\hline WROiC & $\begin{array}{c}\text { SMOOTH( (RWGFCSA + RWGtCOR + RVRbBDO + RWGtCE + } \\
\text { RWGtLOO }) \times 0.01,2)\end{array}$ \\
\hline "3BVS" & $\begin{array}{c}\text { IF THEN ELSE(EItIB }<=0.25 \text {, IF THEN ELSE }(\text { EItIB }<=0.15 \text {, IF THEN } \\
\text { ELSE(EItIB }<=0.05,20,0.7 \times \text { KNiDfD) }, 0.85 \times \text { KNiDfD), KNiDfD) } \\
\text { IF THEN ELSE(LOD }<=5 \text {, IF THEN ELSE(LOD }<=4 \text {, IF THEN } \\
\text { ELSE(LOD }<=3 \text {, IF THEN ELSE( LOD }<=2,40,50), 65), 80), 95)\end{array}$ \\
\hline
\end{tabular}




\section{References}

1. Yuan, H. A model for evaluating the social performance of construction waste management. Waste Manag. 2012, 32, 1218-1228. [CrossRef] [PubMed]

2. Mah, C.M.; Fujiwara, T.; Ho, C.S. Construction and demolition waste generation rates for high-rise buildings in Malaysia. Waste Manag. Res. 2016, 34, 1224-1230. [CrossRef] [PubMed]

3. Ibrahim, M.I.M. Estimating the sustainability returns of recycling construction waste from building projects. Sustain. Cities Soc. 2016, 23, 78-93. [CrossRef]

4. US. Environmental Protection Agency (EPA). Advancing Sustainable Materials Management: 2017 Fact Sheet; U.S. EPA: Washington, DC, USA, 2019.

5. Bakshan, A.; Srour, I.; Chehab, G.; El-fadel, M. A field-based methodology for estimating waste generation rates at various stages of construction projects Resources, Conservation and Recycling A field-based methodology for estimating waste generation rates at various stages of construction projects. Resour. Conserv. Recycl. 2019, 100, 70-80. [CrossRef]

6. Ling, F.Y.Y.; Lim, M.C.H. Implementation of a waste management plan for construction projects in Singapore. Archit. Sci. Rev. 2002, 45, 73-81. [CrossRef]

7. Wang, J.; Yuan, H.; Kang, X.; Lu, W. Critical success factors for on-site sorting of construction waste: A china study. Resour. Conserv. Recycl. 2010, 54, 931-936. [CrossRef]

8. Liu, Z.; Lu, Y.; Peh, L.C. A Review and Scientometric Analysis of Global Building Information Modeling (BIM) Research in the Architecture, Engineering and Construction (AEC) Industry. Buildings 2019, 9, 210. [CrossRef]

9. Lu, W.; Yuan, H. A framework for understanding waste management studies in construction. Waste Manag. 2011, 31, 1252-1260. [CrossRef]

10. Yuan, H.P.; Shen, L.Y.; Hao, J.J.L.; Lu, W.S. A model for cost-benefit analysis of construction and demolition waste management throughout the waste chain. Resour. Resour. Conserv. Recycl. 2011, 55, 604-612. [CrossRef]

11. Wang, C.; Li, Z.; Tam, V.W. Identifying best design strategies for construction waste minimization. J. Clean. Prod. 2015, 92, 237-247. [CrossRef]

12. Jalaei, F.; Zoghi, M.; Khoshand, A. Life cycle environmental impact assessment to manage and optimize construction waste using Building Information Modeling (BIM). Int. J. Constr. Manag. 2019. [CrossRef]

13. Forrester, J.W. Industrial Dynamics: A Major Breakthrough for Decision Makers. Roots Logist. 2012, 36, 141-172.

14. Tam, V.W.; Shen, L.; Tam, C.M. Assessing the levels of material wastage affected by sub-contracting relationships and projects types with their correlations. Build. Environ. 2007, 42, 1471-1477. [CrossRef]

15. Jaillon, L.C.; Poon, C.; Chiang, Y.H. Quantifying the waste reduction potential of using prefabrication in building construction in Hong Kong. Waste Manag. 2009, 29, 309-320. [CrossRef] [PubMed]

16. Abbasianjahromi, H.; Khoshand, A.; Zoghi, M.; Heydarzadeh, M.J. At glance at the world: Effect of construction activities on construction and demolition waste generation in Iran. Waste Manag. 2007, 70. [CrossRef]

17. Innes, S. Developing tools for designing out waste pre-site and on-site. In Proceedings of the Minimizing Construction Waste Conference: Developing Resource Efficiency and Waste Minimization in Design and Construction, London, UK, 21 October 2004.

18. Hannan, M.A.; al Mamun, M.A.; Hussain, A.; Basri, H.; Begum, R.A. A review on technologies and their usage in solid waste monitoring and management systems: Issues and challenges. Waste Manag. 2015, 43, 509-523. [CrossRef]

19. National Institute of Building Sciences (NIBS). National Building Information Modeling Standard-Version 2; National Institutute of Building Sciences: Washington, DC, USA, 2012.

20. Won, J.; Cheng, J.C.P.; Lee, G. Quantification of construction waste prevented by BIM-based design validation: Case studies in South Korea. Waste Manag. 2016, 49, 170-180. [CrossRef]

21. Rajendran, P.; Gomez, C.P. Implementing BIM for waste minimization in the construction industry: A literature review. In Proceedings of the 2nd International Conference on Management, Langkawi Kedah, Malaysia, 1 January 2012; pp. 557-570. 
22. Ahankoob, A.; Khoshnava, S.M.; Rostami, R.; Preece, C. BIM perspectives on construction waste reduction. In Proceedings of the Management in Construction Research Association (MiCRA) Postgraduate Conference, Kuala Lumpur, Malaysia, 5-6 December 2012; pp. 195-199.

23. Motawa, I.; Almarshad, A. A knowledge-based BIM system for building maintenance. Autom. Constr. 2013, 29, 173-182. [CrossRef]

24. Ngwepe, L.; Aigbavboa, C. A theoretical review of building life cycle stages and their related environmental impacts. J. Civil Eng. Environ. Technol. 2015, 2, 7-15.

25. Ragheb, A.F. Towards Environmental Profiling for Office Buildings Using Life Cycle Assessment (LCA). Ph.D. Thesis, University of Michigan, Ann Arbor, MI, USA, 2011.

26. Department for Environment, Food \& Rural Affairs. Demolition and Excavation Waste Generation Estimate; Department for Environment, Food \& Rural Affairs: London, UK, 2012.

27. Guy, B.; Ciarimboli, N. DfD: Design for Disassembly in the Built Environment: A Guide to Closed-loop Design and Building; Hamer Center: Seattle, WA, USA, 2008.

28. Macozoma, D.S. Building Deconstruction, International Council for Research and Innovation in Building And Construction (CIB). December 2001.

29. Tingley, D.D.; Davison, B. Developing an LCA methodology to account for the environmental benefits of design for deconstruction. Build. Environ. 2012, 57, 387-395. [CrossRef]

30. Fishbein, B.K. Building for the Future: Strategies to Reduce Construction and Demolition Waste in Municipal Projects; INFORM, Incorporated: Metro Manila, Philippines, 1998.

31. Chini, A.R.; Balachandran, S. Anticipating and responding to deconstruction through building design. In Proceedings of the Design for Deconstruction and Materials Reuse; CIB Publisher: Montreal, QC, Canada, 2002; Volume 272, pp. 175-185.

32. Snook, K.; Ridout, R.; Turner, A. Recycling Waste from the Construction Site; Chartered Institute of Building: Bracknell, UK, 1995.

33. Kim, S.; Chang, S.; Castro-Lacouture, D. Dynamic Modeling for Analyzing Impacts of Skilled Labor Shortage on Construction Project Management. J. Manag. Eng. 2020, 36, 04019035. [CrossRef]

34. Kollikkathara, N.; Feng, H.; Yu, D. A system dynamic modeling approach for evaluating municipal solid waste generation, landfill capacity and related cost management issues. Waste Manag. 2010, 30, 2194-2203. [CrossRef] [PubMed]

35. Sterman, J.D. Modeling Managerial Behavior: Misperceptions of Feedback in a Dynamic Decision Making Experiment. Manag. Sci. 1989, 35, 321-339. [CrossRef]

36. Sterman, J.D. System Dynamics Modeling: Tools for Learning in a Complex World. Calif. Manag. Rev. 2001, 43, 8-25. [CrossRef]

37. Dyson, B.; Chang, N.-B. Forecasting municipal solid waste generation in a fast-growing urban region with system dynamics modeling. Waste Manag. 2005, 25, 669-679. [CrossRef]

38. Chaerul, M.; Tanaka, M.; Shekdar, A.V. A system dynamics approach for hospital waste management. Waste Manag. 2008, 28, 442-449. [CrossRef]

39. Homer, J.; Oliva, R. Maps and models in system dynamics: A response to Coyle. Syst. Dyn. Rev. 2001, 17, 347-355. [CrossRef]

40. Elmaraghy, A.; Voordijk, H.; Marzouk, M.M. An exploration of BIM and lean interaction in optimizing demolition projects. In Proceedings of the 26th Annual Conference of the International Group for Lean Construction, Chennai, India, 16-22 July 2018; pp. 112-122.

41. Cheng, J.C.P.; Ma, L.Y. A BIM-based system for demolition and renovation waste estimation and planning. Waste Manag. 2013, 33, 1539-1551. [CrossRef]

42. Arditi, D.; Nawakorawit, M. Designing buildings for maintenance: Designers' perspective. J. Arch. Eng. 1999, 5, 107-116. [CrossRef]

43. Miles, F.M.; Wilson, T.G. Managing project risk and the performance envelope. In Proceedings of the APEC'98 Thirteenth Annual Applied Power Electronics Conference and Exposition, Piscataway, NJ, USA, 15-19 February 1998; pp. 247-253.

44. Mollasalehi, S.; Fleming, A.; Talebi, S.; Underwood, J. Development of an Experimental Waste Framework Based on BIM/LEAN Concept in Construction Design. In Proceedings of the 24th Annual Conference of the International Group for Lean Construction, Boston, FL, USA, 18-24 July 2016; pp. 193-202. 
45. Poon, C.; Yu, T.W.; Ng, L.H. A Guide for Managing and Minimizing Building and Demolition Waste; Department of Civil \& Structural Engineering, Hong Kong Polytechnic University: Hong Kong, China, 2001.

46. Grilo, A.; Jardim-Goncalves, R. Value proposition on interoperability of BIM and collaborative working environments. Autom. Constr. 2010, 19, 522-530. [CrossRef]

47. Akinade, O.; Oyedele, L.; Omoteso, K.; Ajayi, S.O.; Bilal, M.; Owolabi, H.A.; Alaka, H.A.; Ayris, L.; Looney, J.H. BIM-based deconstruction tool: Towards essential functionalities. Int. J. Sustain. Built Environ. 2017, 6, 260-271. [CrossRef]

48. Bansal, N. Reduce-Reuse-Recycle: Designing with Salvaged Building Materials; School of Planning and Architecture: New Delhi, India, 2006.

(C) 2020 by the authors. Licensee MDPI, Basel, Switzerland. This article is an open access article distributed under the terms and conditions of the Creative Commons Attribution (CC BY) license (http://creativecommons.org/licenses/by/4.0/). 